\title{
REVIEW
}

\section{Technology and its role in respiratory care}

\author{
*Sheree M Smitha, Sarah L Elkina, Martyn R Partridge \\ a Imperial College Healthcare NHS Trust, St Mary's Hospital, Praed Street, Paddington, London, UK \\ ${ }^{b}$ Imperial College London, NHLI Division at Charing Cross, St Dunstans Road, London, UK
}

Received 31st October 2008; revised version received 24th March 2009; accepted 11th April 2009; online 8th July 2009

\begin{abstract}
Introduction: Telemonitoring, telemedicine, clinical and medical informatics or telecare, are terms used to describe the use of technology along with local clinical protocols to monitor remotely a patient's medical condition in their own home. In respiratory medicine, where large numbers of people have long term conditions such as asthma and chronic obstructive pulmonary disease (COPD), the role of such monitoring technology in the management of patients is of great interest.

Aim: This review seeks to explore what evidence exists to support the deployment of technology to improve the care of people with respiratory conditions.

Method: Narrative review

Result: A wide variety of technologies have been involved in asthma and COPD care, from management systems to self monitoring devices. Many studies report that staff and patients 'liked' the technology. The service, care and financial benefits to both patients and the health care system were less obvious. Many studies suffered from poor methodology and lacked clear endpoints.

Conclusion: There is an enormous potential for telemonitoring to assist in the provision of better care for those with long term lung diseases. However, evidence of benefit is unclear and there remains a need for robust studies and answers to clear research questions for specific patient populations before such technologies can be recommended for widespread implementation.

(C) 2009 General Practice Airways Group. All rights reserved.

SM Smith et al. Prim Care Resp J 2009; 18(3): 159-164.

doi:10.4104/pcrj.2009.00038
\end{abstract}

Keywords informatics, telemedicine, telemonitoring, telecare, telehealth, e-health, COPD, asthma

Contents
Abstract
Introduction
Method
Results
Asthma
COPD
Cost and benefit
Miscussion
Conclusion $\ldots \ldots \ldots \ldots$

\section{See linked editorial by McLean and Sheikh on pg 125}

\section{Introduction}

Telemonitoring, telemedicine, clinical and medical informatics, or telecare, are terms used to describe the use of technology along with local clinical protocols to monitor remotely a patient's medical condition in their own home. The focus upon such health technology and its swift deployment within the UK National Health Service (NHS) through the commissioning of 'demonstration sites' and health service improvement projects', highlights the interest in, and the rapid development of, a variety of health care technologies.

* Corresponding author: Dr Sheree M Smith, Chest and Allergy Unit, St Mary's Hospital, Imperial College Healthcare NHS Trust, 1st Floor Mint Wing, Praed Street, London, W2 1NY, UK. Tel: +44 (0)207 8862349 Fax: +44 (0)207 8861613 E-mail: sheree.smith@imperial.nhs.uk 
SM Smith et al.

These technologies can take any number of forms such as web-based applications, ${ }^{3}$ mobile phone and alert systems, ${ }^{4,5}$ telephone and video conferencing with patients, ${ }^{6,7}$ as well as any combination of these applications. In the last five years there has been a rapid increase in the use of monitoring technology as a management tool for long-term conditions despite a lack of robust evidence of clinical benefit to patients. ${ }^{8}$ Telemedicine as a method of providing healthcare to remote areas is not lacking in evidence of benefit, especially for consultations saved, journeys avoided and diagnoses changed, ${ }^{9}$ but the situation regarding its more general use for monitoring purposes is much less clear.

In respiratory medicine, where large numbers of people have long term conditions such as asthma and chronic obstructive pulmonary disease (COPD), the role of such monitoring technology in the management of patients is of great interest. COPD is a progressive disabling disease affecting an estimated 900,000 people with a total annual cost to the NHS of $\mathrm{f} 982$ million including both direct and indirect costs. ${ }^{10}$ There is often an ongoing burden on patients and their carers, and we need to know whether technology can reduce this burden and which outcomes can expect to be improved. A number of systematic reviews have attempted to summarise the evidence and to date little benefit has been reported. ${ }^{11,12}$ In order to widen the scope of our literature search we have taken a narrative approach to explore the evidence in favour of technology for the monitoring or management of respiratory patients.

Table 1. Asthma search strategy and results.

\begin{tabular}{lccc}
$\begin{array}{l}\text { Diagnosis and Search } \\
\text { term }\end{array}$ & $\begin{array}{c}\text { Pubmed } \\
\mathrm{n}=\end{array}$ & $\begin{array}{c}\text { Cochrane Library } \\
\mathrm{n}=\end{array}$ & $\begin{array}{c}\text { Google } \\
\mathrm{n}=\end{array}$ \\
\hline Asthma and & & 1 & $\begin{array}{c}97,000 \\
22,200\end{array}$ \\
\hline $\begin{array}{l}1 \text { telem* }{ }^{*} \text { telemedicine } \\
\text { and telemonitoring }\end{array}$ & 82 & 0 & 179,000 \\
\hline 2 ehealth & 3 & 1 & 74,100 \\
\hline 3 electronic monitoring & 77 & 4 & 350,000 \\
\hline 4 health technology & 269 & 2 & 180 \\
\hline 5 telehealth & 4 & 0 & 535 \\
\hline 6 telecare & 15 & 0 & 11,000 \\
\hline 1 and NHS & 0 & 0 & 1,010 \\
\hline 2 and NHS & 0 & 0 & 9,080 \\
\hline 3 and NHS & 0 & 0 & 49,300 \\
\hline 4 and NHS & 4 & 0 & 5,630 \\
\hline 5 and NHS & 0 & 0 & 5,680 \\
\hline 6 and NHS & 0 & 820,615 \\
\hline TOTAL & 454 & & \\
& & 0 & 800 \\
\hline
\end{tabular}

\section{Method}

This review was undertaken using a narrative synthesis approach to examine a broad range of literature in order to provide an overview on the topic of technology and respiratory care in an attempt to understand the current level of NHS commissioning of telemonitoring facilities. Furthermore, in this narrative review we sought literature pertaining to a variety of technologies, from management systems to hand held devices, to assess the support for each technology and to distinguish areas for future research.

Publications on asthma and COPD that were linked with telemedicine, telemonitoring, e-health, telehealth, telecare, electronic monitoring and health technology were sought by searching the following databases: Pubmed; Cochrane Library; and Google - for information in the public forum, including government agencies and patient advocacy websites. Key words and terms used in the search were: COPD; asthma; telem*; ehealth; electronic monitoring; health technology; telehealth; telecare; and NHS. The results for asthma and COPD are displayed in separate tables (Tables 1 and 2). The truncation of telemedicine and telemonitoring words to telem* (use of wild card term) could only be utilised in the Pubmed searches and the full term/word was used in both Cochrane and Google searches. Similarly, National Health Service was shortened to NHS to provide consistency for all three database searches. For the purposes of this narrative review duplicates were not removed from the numerical results of the search strategy since the focus was a narrative synthesis of the literature.

\section{Table 2. COPD search strategy and results}

\begin{tabular}{lccc}
$\begin{array}{l}\text { Diagnosis and Search } \\
\text { term }\end{array}$ & $\begin{array}{c}\text { Pubmed } \\
\mathrm{n}=\end{array}$ & $\begin{array}{c}\text { Cochrane Library } \\
\mathrm{n}=\end{array}$ & $\begin{array}{c}\text { Google } \\
\mathrm{n}=\end{array}$ \\
\hline COPD and & & 5 & 39,400 \\
\hline $\begin{array}{l}1 \text { telem* }{ }^{*} \text { telemedicine } \\
\text { and telemonitoring }\end{array}$ & 65 & 1 & 32,300 \\
\hline 2 ehealth & 5 & 2 & 18,900 \\
\hline 3 electronic monitoring & 15 & 5 & 134,000 \\
\hline 4 health technology & 115 & 2 & 24,100 \\
\hline 5 telehealth & 12 & 2 & 12,400 \\
\hline 6 telecare & 14 & 0 & 10,100 \\
\hline 1 and NHS & 2 & 0 & 871 \\
\hline 2 and NHS & 0 & 0 & 5,990 \\
\hline 3 and NHS & 0 & 0 & 14,900 \\
\hline 4 and NHS & 5 & 0 & 12,200 \\
\hline 5 and NHS & 0 & 1 & 8,650 \\
\hline 6 and NHS & 1 & 18 & 341,721 \\
\hline TOTAL & 234 & & \\
\hline
\end{tabular}




\section{Results}

A plethora of technology-based monitoring studies have been undertaken in the last decade using a variety of methodologies. Monitoring of respiratory conditions by both health care professionals and patients is strongly recommended in both asthma and COPD guidelines. ${ }^{12}$ In some instances the guideline itself forms the basis of the technological intervention as part of a decision-making system for clinicians in primary care and other health care providers. ${ }^{13,14}$

\section{Asthma}

Asthma monitoring has been the focus of extensive research in the past decade. Many of these studies have focused on patient monitoring through the use of diary cards, ${ }^{15}$ peak flow meters $^{16}$ and symptom scoring, ${ }^{17}$ with the ultimate aim of improving patients' awareness and self management behaviour. Asthma studies using technology studies have also sought to manage, prompt and change behaviour. ${ }^{18,19}$ More recently, there has been a focus on data mining of electronic records for case finding of co-morbid conditions. ${ }^{20,21}$ However, much of the technology-based asthma literature pertains to various types of case management, including measures for surveillance to facilitate various formats of outreach care and education. ${ }^{4,22-25}$ Technology has also been used as a patient compliance feature through an electronic patient alert and dispensing log system utilizing an audio reminder alert. ${ }^{26}$ However, at the heart of quality asthma care is the concept of shared decision making, and asthma guidelines strongly promote this concept. ${ }^{27}$ If asthma care concordance between patient and provider is to be achieved, the question of whether technology impacts on this process is yet to be ascertained.

\section{COPD}

For people with COPD, acute exacerbations of COPD symptoms (AECOPD) are common; whilst some are unreported $^{28}$ others result in visits to the emergency department and hospitalisation, ${ }^{29}$ and exacerbations of the disease are the feature most feared by patients. ${ }^{30} \mathrm{~A}$ third of these patients will be seen again or admitted to hospital within the subsequent eight weeks. ${ }^{31}$ This would seem to be an area where good studies are needed to determine whether technology can aid identification of those making a delayed recovery and to prompt identification of those needing further treatment or readmission. Recent studies have not provided the evidence needed to support the addition of technology and have contained methodological issues concerning small sample sizes, ${ }^{32-34}$ lack of allocation concealment, ${ }^{35}$ and additional access to health services available to patients in the technology arm. ${ }^{36}$ Patients with recurrent $A E C O P D$ have been identified as having a more rapid decline in lung function ${ }^{37}$ and a reduced quality of life. ${ }^{38}$
As yet the case for the addition of monitoring and management technologies to current 'best' practice for the ongoing care of COPD patients is weak and usual care in some studies may not meet 'best' practice standards for this patient group - such as outreach programmes, hospital at home, and early supportive discharge services espoused in national and international guidelines. ${ }^{39,40}$ For COPD patients who undertake pulmonary rehabilitation there is some evidence that technology may be useful as a motivator to sustain the exercise component after the initial programme is completed..$^{41}$

\section{Technology versus face to face}

At present there is evidence that patients 'are positive towards' health technology ${ }^{8,42,43}$ although the clinical benefit has not been firmly established. ${ }^{44}$ As many people with severe COPD are housebound, a cyber link to the health professional through telemonitoring may be enticing to some hospital and primary care trusts. As a preliminary it is therefore important to establish how many of our patients with COPD, particularly those in the severe disease group, have internet access, a terrestrial phone line and are capable of using this type of telecommunications. Furthermore, as regards patients who rely on the technology to convey their health status to the health team, this may in itself create another area of research since no studies thus far have explored the emotional effects on patients and their carers when the telemonitoring service is withdrawn. Understanding any emotional impact is particularly important for any COPD population as co-morbid conditions such as anxiety and depression are already well documented in this patient group. ${ }^{45}$ In the US, telemonitoring has been expanded to the realm of 'standard' care and is currently offered by some insurance companies (for a number of reasons), with a reduction in face-to-face nurse visits, without supporting evidence of better health outcomes. ${ }^{46}$

\section{Cost and benefit}

In assessing the cost and benefit of technology, the cost of the technology and the time to view the data is rarely reported. Primarily, the reduction of current service cost seems to warrant the attention of a number of studies. ${ }^{7,33}$ It is unclear from some of the published studies on technology whether researchers were required to pay for the equipment used to undertake the research. The added costs of providing telecommunications and additional equipment such as weight scales $^{47}$ to these patients are unknown, as are the costs for the ubiquitous technology upgrades and criteria such as which patients should have the service and over what period of time is required for maximal clinical improvement.

\section{Methodological Issues}

Innovation and new technology is exciting and to be welcomed and we advocate that there is an urgent need for clinical trials of health technology for the monitoring of those 
with asthma and COPD and that money should not be spent on such interventions outside clinical trials. Such studies should be robust in design and regarded as the norm for such interventions in a similar way that we expect trials of new pharmaceutical agents to be undertaken. One study found that $25 \%$ of their COPD study population had severe comorbid conditions and were subsequently excluded, as were a further $10 \%$ of patients due to problems associated with health literacy or not having a terrestrial phone line. ${ }^{36}$ Inclusion and exclusion criteria of published studies thus raise issues associated with the use of health technology and social disadvantage. A more rigorous approach to such interventional research is needed to provide answers to questions associated with the advantages and disadvantages for this proposed addition to care.

\section{Discussion}

Despite there being a large number of studies of a variety of technologies it remains difficult to ascertain the exact role and benefit which technology offers the health care system. In a recent heart failure study, technology was perceived to have a reduced impact due to the high quality of standard care by the outreach heart failure nursing team. ${ }^{48}$ Cowie and colleagues' findings concur with other research on the effect of multidisciplinary teams (MDTs) which demonstrate that when best practice is operationalised there may not be a need for additional services. ${ }^{49}$ Whilst technology may assist in the management of patients alongside best practice, it remains to be seen if there is a reduction in mortality, morbidity - and conversely an increase in quality of life - that can be solely assigned to the addition of technology.

While the arguments in favour a technological intervention such as the monitoring of patients in their home is plausible, it is unclear if technology either promotes the resolution of symptoms and/or empowers the patient to self manage their condition or both. Self management education and the use of action plans can alter patient behaviour with a beneficial effect on outcomes, ${ }^{29,50}$ and monitoring via the use of technology may be used to reinforce such behaviour - but its benefits need to be proved. Equally it is possible that dependence upon advice received back in response to technology-based monitoring could reinforce dependent behaviours. Such a worse case scenario may see patients passively accepting the tele-commuted information and then consequently the dissolution of concordance in health care decision-making begins. Studies that tease out the issues connected to patient monitoring and an understanding of the factors involved in the patient's transition to self management through the use of technology are needed. In asthma, a number of studies have sought to understand how technology can be used effectively in self management, and as yet the benefit for the use of this type of intervention remains unclear. ${ }^{4,51}$

Many of the systematic reviews of technological-based interventions highlighted methodological concerns. Drug development has well established interconnected processes from early development through to human trials, and this procedural approach may benefit future technology-based studies. ${ }^{52}$ Due to the limited longevity of technology, it would be reasonable to consider fewer stages in technological assessment, but the real-time studies need to be in large populations to provide definite evidence of benefit. The role of the National Institute for Health and Clinical Excellence (NICE) in assessing the benefits of technology has become clear with their recently-released 'Guidance for technology appraisal'. ${ }^{53}$ The transparency within both of these research and evaluative processes needs to be at the forefront of any health technology study to ensure that sound evidence can be translated into health service practice.

From a patient perspective, some studies suggest that patients with severe illness are accepting of care and rarely voice concern; however, we believe this not to be a reason to advocate advancement in technology without robust

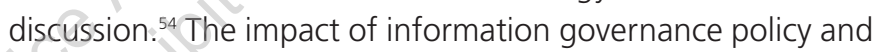
procedures on the use of technology in case management is yet to be determined as the NHS strives to contain breaches in patient information and the loss of computerised data. If many of these technology-based studies are to be translated into clinical care then clearly the transmission of identifiable patient information through telecommunication networks may need further wide-ranging discussion. This canvassing of opinion and development of policy will be crucial given the recent experience of the NHS's comprehensive record system (CRS) and the NHS patients' forum on this topic. ${ }^{55,56}$ Finally, the need for robust studies that include diversity and information governance assessments are required to understand the benefit or limitations which technology has to offer the health service and patients with chronic respiratory conditions.

\section{Conclusion}

Although there may be an enormous potential for telemonitoring and the use of other forms of technology to assist in the provision of better care for those with long term respiratory diseases, at the present time there are too many unanswered questions for the implementation of this form of health technology across the NHS. More robust studies, and answers to clear research questions for specific patient populations, are needed, but we remain hopeful that telemonitoring and the use of technology as a supplement to best practice may prove to be a useful addition to the UK $\mathrm{NHS}$. 


\section{Conflict of interest}

None to declare.

\section{References}

1. Unknown. Nottingham PCT launches large-scale telemonitoring of chronic disease patients. The Birchley Hall Press; 2008 [cited 2008 19/08/08]; Available from: http://www.bjhcim.co.uk/news/2008/n803034

2. Dale J, Connor S, Tolley K. An evaluation of the west Surrey telemedicine monitoring project. J Telemed Telecare 2003;9(Suppl 1):S39-\$41. http://dx.doi.org/10.1258/135763303322196295

3. Hernandez C, Casas A, Escarrabill J, et al. Home hospitalisation of exacerbated chronic obstructive pulmonary disease patients. Eur Resp J 2003;21:58-67 http://dx.doi.org/10.1183/09031936.03.00015603

4. Pinnock H, Slack R, Paglairi C, Price D, Sheikh A. Understanding the potential role of mobile phone-based monitoring and asthma self management of asthma: qualitative study. Clin Exp Allergy 2007;37(5):794-802. http://dx.doi.org/10.1111/j.1365-2222.2007.02708.x

5. Lee RG, Chen KC, Haiso C, Tseng CL. Mobile care system with an alert mechanism. IEEE Trans Inf Technol Biomed 2007;11(5):507-17 http://dx.doi.org/10.1109/TITB.2006.888701

6. Finkelstein SM, Speedie SM, Potthoff S. Home Telehealth Improves Clinical Outcomes at Lower Cost for Home Healthcare. Telemed J E-Health 2006;12(2):128-36.

7. Johnston B, Wheeler L, Deuser J, Sousa KH. Outcomes of the Kaiser Permanente Tele-Home Health Research Project. Arch Fam Med 2000;9:40-5 http://dx.doi.org/10.1001/archfami.9.1.40

8. Currell R, Urquhart C, Wainwright $P, R$. L. Telemedicine versus face to face patient care: effects on professional practice and health care outcomes. Cochrane Database of Systematic Reviews 2000(2): http://dx.doi.org/10.1002/14651858.CD002098

9. Raza T, Joshi M, Schapira RM, Agha Z. Pulmonary telemedicine - A model to access the subspecialist services in underserved rural areas. Int J of Med Inform 2009;78:53-9. http://dx.doi.org/10.1016/ j.ijmedinf.2008.07.010.

10. National Collaborating Centre for Chronic Conditions. Chronic obstructive pulmonary disease: Management of chronic obstructive pulmonary disease in adults in primary and secondary care. London: National Institute for Clinical Excellence; 2004

11. Pare G, Jaana M, Sicotte C. Systematic Review of Home Telemonitoring for Chronic Diseases: The Evidence Base. J Am Med Inform Assoc 2007;14(3):26977. http://dx.doi.org/10.1197/jamia.M2270

12. Car J, Black A, Anandan C, et al. The Impact of eHealth on the Quality \& Safety of Healthcare - A Systematic Overview \& Synthesis of the Literature. ondon: Imperial College London and The University of Edinburgh 2008, March 2008.

13. Eccles M, McColl E, Steen $N$, et al. Effect of computerised evidence based guidelines on management of asthma and angina in adults in primary care: cluster randomised controlled trial. BMJ 2002;325:941-4. http://dx.doi.org/10.1136/bmj.325.7370.941

14. Cooper CB. Respiratory applications of telemedicine. Thorax 2009;64(3):18991. http://dx.doi.org/10.1136/thx.2008.104810

15. Valerio MA, Parker EA, Couper MP, Connell CM, Janz NK. Demographic and clinical characteristics predictive of asthma diary use among women. J Asthma 2008;45(5):357-61. http://dx.doi.org/10.1080/02770900801956405

16. Reddel HK, Toelle BG, Marks GB, Ware SI, Jenkins CR, Woolcock AJ. Analysis of adherence to peak flow monitoring when recording of data is electronically. BMJ 2002;324:146-7. http://dx.doi.org/10.1136/bmj.324.7330.146

17. Cote J, Cartier A, Robichaud $P$, et al. Influence on asthma morbidity of asthma education programs based on self management plans following treatment optimization. Am J Resp Crit Care Med 1997;155(5):1509-14.

18. Willems DC, Joore MA, Hendriks JJ, Nieman FH, Severens JL, Wouter EF. The effectiveness of nurse-led telemonitoring of asthma: results of a randomized controlled trial. J Eval Clin Pract 2008;14(4):600-09. http://dx.doi.org/ 10.1111/j.1365-2753.2007.00936.x

19. de jongste JC, Carraro S, Hop WC, Charism Study Group. Daily monitoring of exhaled nitric oxide and symptoms in the treatment of childhood asthma. Am J Resp Crit Care Med 2009;179(2):93-7

20. Himes BE, Dai Y, Kohane TS, Weiss ST, Ramoni MF. Prediction of Chronic Obstructive Pulmonary Disease (COPD) in Asthma patients using Electronic Medical Records. J Am Med Inform Assoc 2009;16:371-9.

21. Cleland J, Cladow J, Ryan D. A qualitative study of the attitude of patients and staff to the use of mobile phone tchnology for the recording and gathering of asthma data. J Telemed Telecare 2007;13(2):85-9. http://dx.doi.org/ 10.1258/135763307780096230

22. Chan DS, Callahan CW, Hatch-Pigott VB, et al. Internet-based home monitoring and education of children with asthma is comparable to ideal office-based care: results of a 1 year asthma in-home monitoring trial. Pediatrics 2007;119(3):569-78. http://dx.doi.org/10.1542/peds.2006-1884

23. Wood J, Yablochnikov I, Finklestein J. Interactive asthma learning system utilizing a mobile phone platform. AMIA Annual Symp Proc 2008;Nov 61181.

24. Pinnock H, Slack R, Pagliari C, Price D, Sheikh A. Professional and patient attitudes to using mobile phone technology to monitor asthma: a questionnaire survey. Prim Care Resp J 2006;15(4):237-45. http://dx.doi.org/10.1016/ j.pcrj.2006.03.001

25. Runge C, Lecheler J, Horn M, Tews JT, Schaefer M. Outcomes of a web-based patient education program for asthma children and adolescents. Chest 2006;129(3):581-93. http://dx.doi.org/10.1378/chest.129.3.581

26. Charles T, Quinn D, Weatherall M, Aldington S, Beasley R, Holt S. An audiovisual reminder function improves adherence with inhaled corticosteroid therapy in asthma. J Allergy and Clin Immunol 2007;119(4):811-16. http://dx.doi.org/10.1016/j.jaci.2006.11.700

27. British Thoracic Society Scottish Intercollegiate Guidelines Network. British Guideline on the Management of Asthma. Thorax 2008;63(Suppl 4):iv1-iv121. http://dx.doi.org/10.1136/thx.2008.097741

28. Langsetmo L, Platt RW, Ernst P, Bourbeau J. Under reporting exacerbation of chronic obstructive pulmonary disease in a longitudinal cohort. Am J Resp Crit Care Med 2008;177(4):396-401. http://dx.doi.org/10.1164/rccm.200708$12900 \mathrm{C}$

29. Bourbeau J, Julien M, Maltais F, et al. Reduction of Hospital Utilization in Patients with Chronic Obstructive Pulmonary Disease. Arch Intern Med 2003;163:585-91. http://dx.doi.org/10.1001/archinte.163.5.585

30. Haughney J, Partridge MR, Vogelmeier C, et al. Exacerbations of COPD: quantifiying the patient's perspective using discrete choice modelling. Eur Resp J 2005;26(4):623-9. http://dx.doi.org/10.1183/09031936.05.00142704

31. Skwarska E, Cohen G, Skwarski KM, et al. Randomised controlled trial of supported discharge in patients with exacerbations of chronic obstructive pulmonary disease. Thorax 2000;55:907-12. http://dx.doi.org/ 10.1136/thorax.55.11.907

32. Maiolo C, Mohamed El, Fiorani CM, de Lorenzo A. Home telemonitoring for patients with severe respiratory illness: the Italian experience. J Telemed Telecare 2003;9:67-71. http://dx.doi.org/10.1258/135763303321327902

33. Pare G, Sicotte C, St-Jules D, Gauthier R. Cost-minimization analysis of a telehomecare program for patients with chronic obstructive pulmonary disease. Telemed J E-Health 2006;12(2):114-21.

34. Vontetsionos TH, Giovas $\mathrm{P}$, Katsaras $\mathrm{TH}$, et al. Telemedicine-assisted home support for patients with advanced chronic obstructive pulmonary disease: preliminary results after nine-month follow-up. J Telemed Telecare 2005;11(Suppl 1):S86-8. http://dx.doi.org/10.1258/1357633054461697

35. Trappenburg JCA, Niedink A, de Weert-van Oene GH, et al. Effects of telemonitoring in patients with chronic obstructive pulmonary disease. Telemed J E-Health 2008;14(2):138-46.

36. Casas A, Troosters T, Garcia-Aymerich J, et al. Integrated care prevents 
SM Smith et al.

hospitalisations for exacerbations in COPD patients. Eur Resp J 2006;28:12330. http://dx.doi.org/10.1183/09031936.06.00063205

37. Wedzicha JA, Donaldson GC. Exacerbations of chronic obstructive pulmonary disease. Respiratory Care 2003;48(12):1204-13.

38. Llor C, Molina J, Naberan K, et al. Exacerbations worsen the quality of life of chronic obstructive pulmonary disease patients in primary healthcare. Int J Clin Pract 2008;62(4):585-92. http://dx.doi.org/10.1111/j.1742-1241.2008. 01707.x

39. British Thoracic Society Guideline Development Group. Intermediate care Hospital at Home in chronic obstructive pulmonary disease: British Thoracic Society guideline. Thorax 2007;62:200-10. http://dx.doi.org/ 10.1136/thx.2006.064931

40. Celli BR, MacNee W, and committee members. Standards for the diagnosis and treatment of patients with COPD: a summary of the ATS/ERS position paper. Eur Resp J 2004;23:932-46. http://dx.doi.org/10.1183/09031936.04. 00014304

41. Marshall A, Medvedev O, Antonov A. Use of a smartphone for improved self management of pulmonary rehabilitation. Int J Telemed App/ 2008 ID 753064 p 1-5. http://dx.doi.org/10.1155/2008/753064

42. Schmidt S, Sheikzadeh S, Beil B, Patten M, Stettin J. Acceptance of Telemonitoring to Enhance Compliance in Patients with Chronic Heart Failure. Telemed J E-Health 2008;14(5):426-33.

43. Mair FS, Goldstein P, May C, et al. Patient and provider perspectives on home telecare: preliminary results from a randomized controlled trial. J Telemed Telecare 2005;11(Suppl 1):S95-S7. http://dx.doi.org/10.1258/ 1357633054461976

44. Roca J, Alonso A, Hernandez C. Integrated care for COPD patients: time for extensive deployment. Breathe 2008;5(1):27-35.

45. Quint JK, Baghai-Ravary R, Donaldson GC, Wedzicha JA. Relationship between depression and exacerbation in COPD. Eur Resp J 2008;32:53-60. http://dx.doi.org/10.1183/09031936.00120107

46. Blue Cross and Blue Shield Minnesota. CHF/COPD telemonitoring services for CareBlue and SecureBlue Provider Bulletin. Minnesota 2008 [cited 2008 June 20]; Available from: http://www.bluecrossmn.com/bc/wcs/groups/bcbsmn/ @mbc_bluecrossmn/documents/public/post71a_118470.pdf.

47. Clark RA, Inglis SC, McAlister FA, Cleland JG, Stewart S. Telemonitoring or structure telephone support programmes for patients with chronic heart failure: a systematic review and meta-analysis. BMJ 2007;334(7600):942. http://dx.doi.org/10.1136/bmj.39156.536968.55

48. Dar O, Riley J, Chapman C, et al. A randomized trial of home monitoring in a typical elderly heart failure population in North West London: results of the Home-HF study. Eur J Heart Failure 2009;11:319-25. http://dx.doi.org/10.1093/eurjhf/hfn050

49. Jaarsma $\mathrm{T}$, van der Wal MH, Leesman-Leegte I, et al. Effect of moderate or intensive disease management program on outcome in patients with heart failure: Coordinating Study Evaluating Outcomes of Advising and Counseling in Heart Failure (COACH). Arch Int Med 2008;168(3):316-24. http://dx.doi.org/10.1001/archinternmed.2007.83

50. Sridhar M, Taylor R, Dawson S, Roberts NJ, Partridge MR. A nurse led intermediate care package in patients who have been hospitalised with an acute exacerbation of chronic obstructive pulmonary disease. Thorax 2008;63:194-200. http://dx.doi.org/10.1136/thx.2007.077578

51. Lee HR, Yoo SK, Jung SM, Kwon NY, Hong SC. A web-based mobile asthma management system. J Telemed Telecare 2005;11(Suppl 1):56-9. http://dx.doi.org/10.1258/1357633054461598

52. Aarons L, Balant L, Boobis A. COST B15: modeling in drug development. Br J Clin Pharmacol 2001;52(1):118-19. http://dx.doi.org/10.1046/j.03065251.2001.01408.x

53. National Institute for Health and Clinical Excellence. About technology appraisals. London: NICE; 2008 [cited 2008 24/10/2008]; Available from: http://www.nice.org.uk/aboutnice/whatwedo/abouttechnologyappraisals/abou t_technology_appraisals.jsp.

54. Habraken JM, Pols J, Bindels PJE, Willems DL. The silence of patients with endstage COPD: a qualitative study. $\mathrm{Br} J$ Gen Pract 2008;58:844-9. http://dx.doi.org/10.3399/bjgp08X376186

55. Department of Health. Patient confidentiality and access to health records. 2009 [cited 200923 Feb]; Available from: http://www.dh.gov.uk/en/ Managingyourorganisation/Informationpolicy/Patientconfidentialityandcaldicot tguardians/index.htm.

56. Pinnock H, Slack R, Shiekh A. Misconnecting for health: (lack of) advice for health professionals on the safe use of mobile phone technology. Qual, Safety and Health Care 2007;16(3):162-3. http://dx.doi.org/10.1136/ qshc. 2006.021345

\section{Available online at http://www.thepcrj.org}

